\title{
Anticorrosive properties of Spiramycin for aluminum in acidic medium
}

\author{
T.A. Alkarim, ${ }^{1}$ K.F. Al-Azawi ${ }^{1 *}$ and R.A. Anaee ${ }^{2}$ \\ ${ }^{1}$ Applied Science Department, University of Technology, Alsinaa Street, Baghdad 10001, \\ Iraq \\ ${ }^{2}$ Department of Materials Engineering, University of Technology, Alsinaa Street, Baghdad \\ 10001, Iraq \\ *E-mail: 100122@uotechnologh.edu.iq
}

\begin{abstract}
Aluminum corrosion is a challenge in manufacture processes where this metal and its alloys are exposed to acid solutions. In the presence of a corrosion inhibitor, the damage to the aluminum surface is reduced significantly, meaning that the surface morphology is more protected due to the adsorption of inhibitor molecules onto the aluminum surface. Expired Spiramycin was investigated as a green corrosion inhibitor for pure aluminum in $0.1 \mathrm{M} \mathrm{HCl}$ solution at 293, 303 313 and $323 \mathrm{~K}$ using the electrochemical method. Three concentrations (100, 150 and $200 \mathrm{ppm})$ of the drug were used. Corrosion testing showed good inhibition efficiencies (IE\%) in $0.1 \mathrm{M}$ $\mathrm{HCl}$ medium reaching $98.836 \%$ at an inhibitor concentration of $200 \mathrm{ppm}$ and $293 \mathrm{~K}$. The adsorption of Spiramycin on pure aluminum surface followed a Langmuir adsorption isotherm. Corrosion potentials revealed that Spiramycin acts as a mixed type inhibitor. Examination of the inhibited surface by SEM confirmed the adsorption of the drug molecules onto the aluminum surface. Furthermore, EDX analysis was performed. It can be observed that aluminum surface contains a percentage of carbon, hydrogen, and oxygen atoms from the adsorbed drug molecules. AFM indicated that the drug molecules contributed to the formation a protective layer by adsorption on the aluminum surface. A FTIR spectral study showed that the protective deposit consisted of a metal-drug complex. The IR adsorption peaks were attributed to some functional groups of the inhibitor molecules adsorbed on the aluminum surface. Adsorption isotherm calculations indicated that the inhibitor underwent physical adsorption.
\end{abstract}

Received: May 23, 2021. Published: August 30, 2021

doi: $\underline{10.17675 / 2305-6894-2021-10-3-20}$

Keywords: expired drug, Spiramycin, corrosion inhibition, aluminum, Tafel plots.

\section{Introduction}

The reaction between the metal surface and its environment that degrades the properties of the material by chemical or electrochemical attack is called corrosion [1]. Studies on the mechanism of the corrosion of aluminum $(\mathrm{Al})$ and its alloys continues to be of great interest due to their technological importance and industrial application, especially in household appliances, containers, electronic devices, cars and airplanes. Aluminum is noted for its relatively low metal density, softness, and non-magnetic properties [2,3]. Inhibitory 
substances are chemicals (natural or synthetic) added to the corrosive environment at low concentrations [4]. Inhibitors can be adsorbed on the metal surface by forming complexes between organic molecules that contain metal ions and a functional group or may participate in cathodic and anodic sites [5]. These inhibitors have extended $\pi$-electronic systems and functional groups (e.g. $-\mathrm{C}=\mathrm{C}-,-\mathrm{OR},-\mathrm{NR}_{2},-\mathrm{OH},-\mathrm{NH}_{2}$ and $\left.-\mathrm{SR}\right)$. Drugs are cheap, nontoxic, and have little negative environmental impacts, so they were suggested for replacing the traditional toxic corrosion inhibitors. The selection of some drugs as corrosion inhibitors is based on the following: (a) the drug molecules contain nitrogen, oxygen, and sulfur as active centers; (b) the drugs are reportedly environmentally friendly and also important in biological reactions; (c) drugs can be easily produced and purified [6]. Drugs retain at least $90 \%$ of their original potency even after the expiration date but their used for medical purposes is restricted due to professional limitations and liability concerns [7].

The use of expired drugs such as green corrosion inhibitors has attracted great attention due to their antibacterial and antifungal effects and the potential to reduce bio-corrosion. Most drugs are organic molecules that contain functional groups. The electronic density on the latter enhances the attraction of the inhibitor particles to metal surfaces through adsorption [8].

Previous studies dealt with the use of expired drugs as corrosion inhibitors for aluminum in acid media, including: antiemitic drug (meclizine hydrochloride) [9], antihypertensive drugs (Enalapril maleate, Atenolol, Etilefrine hydrochloride) [10], polyethylene glycol and Ciprofloxacin [11], Gentamicin, Kanamycin and Amikacin [12], Voltaren [13], Cefuroxime Axetil [14], Chloroquine [15], Cidamex [16], Caffeine [17], antibacterial drugs (penicillin, methicillin and nafcillin) [18], Theophylline Anhydrous [19], antibiotics drugs (Streptomycin and Tetracycline ) [20], Cefixime [21], Alprazolam [22], Cefadroxil [23], Tramadol [24], Cefadroxil and Dicloxacillin [25], Nicotinamide [26], Antifebrin [27], Analgin [28], Naproxen [29], Sildenafil [30], and Suphtrim [31]. They have proven to be good inhibitors; these studies used polarization measurements of the inhibition process as well as thermodynamic, kinetic studies and adsorption isotherms.

This study aimed at the inhibition of the corrosion of pure aluminum by expired Spiramycin at various concentrations $(100,150$ and $200 \mathrm{ppm})$ in $0.1 \mathrm{M}$ hydrochloric acid at $20,30,40$ and $50^{\circ} \mathrm{C}$. Potentiostatic measurements and associated calculations confirmed the inhibitive effect of the investigated drug. The molecular structure of Spiramycin is given in Figure 1.

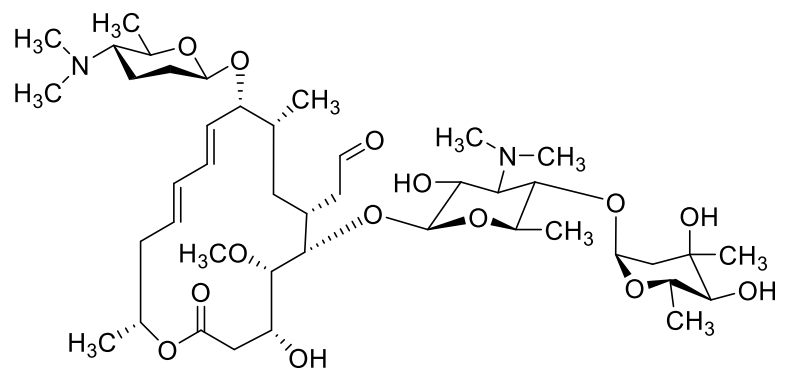

Figure 1. Schematic representation of Spiramycin structure. 


\section{Materials and Methods}

\subsection{Chemicals}

Square shaped samples were cut from pure aluminum with the following chemical composition (\%): Si 0.41, Fe 0.40, Cu 0.11, Mn 0.040, Mg 0.04, Cr 0.0, Zn 0.10, Ti 0.0 and $\mathrm{Al}$ 99.0. The samples were then grinded and polished using emery papers (600 to 3000) to obtain a flat surface. The polished samples were subsequently degreased with acetone and washed with distilled water. The $0.1 \mathrm{M} \mathrm{HCl}$ test solution was prepared by dilution of analytical grade stock (Merck) with water. Spiramycin was purchased from a medicine shop and three separate concentrations were added to the corrosive medium (100, 150 and $200 \mathrm{ppm}$ ) by dissolving the specified amounts of the inhibitor.

\subsection{Active material tests}

The active material in the drug was studied by high performance liquid chromatography (HPLC) to identify the recovery materials. The instrument was obtained from Japan, model: Shimadzu, LC2010A, column dimensions $25 \mathrm{~cm} \times 4.6 \mathrm{~cm}, 50 \%$ methanol $/ 0.1 \mathrm{mM}$ ammonium sulphate as a solvent, wavelength $(\lambda) 210 \mathrm{~nm}$, and flow rate $0.8 \mathrm{ml} / \mathrm{min}$.

The extracted active material was studied for antibacterial efficiency using the well diffusion method. Gram positive Staphylococcus aureus, Streptococcus epidermidis and negative bacteria including Escherichia coli, Klebsiella sp. and Candida albicans were used. Suspension from the main culture was isolated with $4 \mathrm{~mL}$ of normal saline into a test tube, distributed on agar medium (Mueller Hinton), and left for $10 \mathrm{~min}$ to dry. Four wells $(8 \mathrm{~mm}$ ) were cut from the agar by a sterile cork borer, and $50 \mu \mathrm{L}$ of each concentration of the inhibitor (100-200 ppm) was added to the wells. The Petri plates were incubated for $24 \mathrm{~h}$ at $310 \mathrm{~K}$ to grow the bacteria. The diameter of the zone of inhibition was measured (in $\mathrm{mm}$ ) and used as a measure of antibacterial activity.

\subsection{Electrochemical measurements}

A potentiostat/galvanostat M Lab 200 (Germany) was used to measure the electrochemical parameters with a three-electrode cell, using a Pt auxiliary electrode, a saturated calomel electrode (SCE) reference electrode; and the prepared steel specimens as the working electrode. All experiments were performed at 293, 303, 313 and $323 \mathrm{~K}$ using a water bath to control the temperature. The Tafel extrapolation method was used to measure the corrosion potential $\left(E_{\text {corr }}\right)$, corrosion current density $\left(i_{\text {corr }}\right)$, and Tafel slopes $\left(b_{\mathrm{c}}\right.$ and $\left.b_{\mathrm{a}}\right)$.

\subsection{Inspections}

The surfaces used for the inhibition studies were imaged using scanning electron microscopy (SEM), energy dispersive X-ray (EDX), and Fourier transform infrared (FTIR) spectroscopy of the film formed of the adsorbed drug using a $\mathrm{KBr}$ disc. 


\section{Results and Discussion}

\subsection{Tests for the active material in the drug sample}

The recovery of active material from the expired Spiramycin was performed via HPLC, as illustrated in Figure 2. This figure indicates the presence of active materials in the big curve compared with the standard material in the small figure. This test confirmed that the active drug material was obtained.

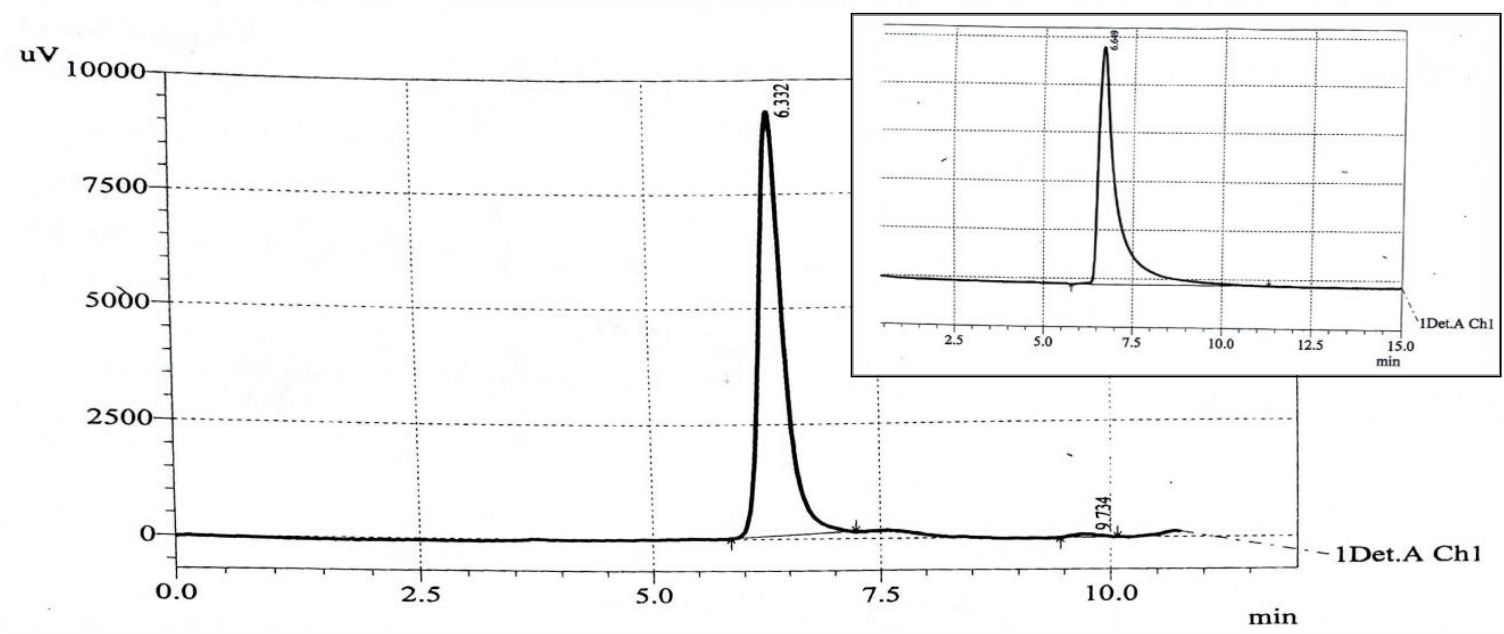

Figure 2. HPLC analysis for the extracted active material from the drug compared with the standard material in the small figure.

The antibacterial activity of expired Spiramycin was studied using the well diffusion method and the results are shown in Figure 3. The inhibition zone against bacteria was measured in $\mathrm{mm}$ and the related results are listed in Table 1. The antibacterial properties of the expired Spiramycin induced cell death. Spiramycin has a good antibacterial activity against both gram positive and negative bacterial cultures.

Table 1. Data of antibacterial test.

\begin{tabular}{ccccc} 
Type of bacteria & $\mathbf{0 . 2}$ & $\mathbf{0 . 4}$ & $\mathbf{0 . 6}$ & $\mathbf{0 . 8}$ \\
\cline { 2 - 5 } & 39 & 40 & 43 & 43 \\
Staphylococcus aureus & 39 & 42 & 44 & 45 \\
Staphylococcu epidermidis & 23 & 25 & 25 & 26 \\
Escherichia coli & 20 & 22 & 23 & 25 \\
Klebsiella sp. & 36 & 40 & 40 & 45
\end{tabular}




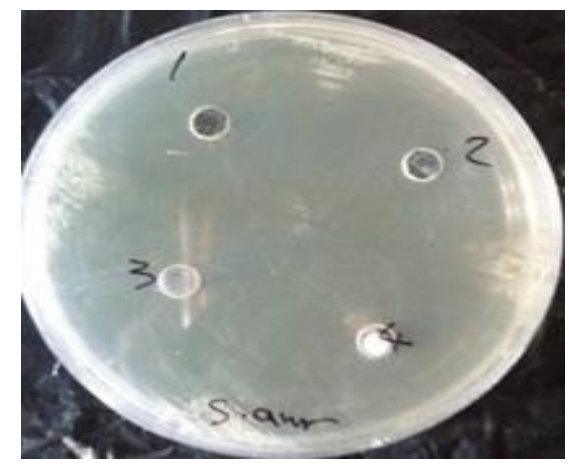

Staphylococcus aureus



Streptococcus epidermidis

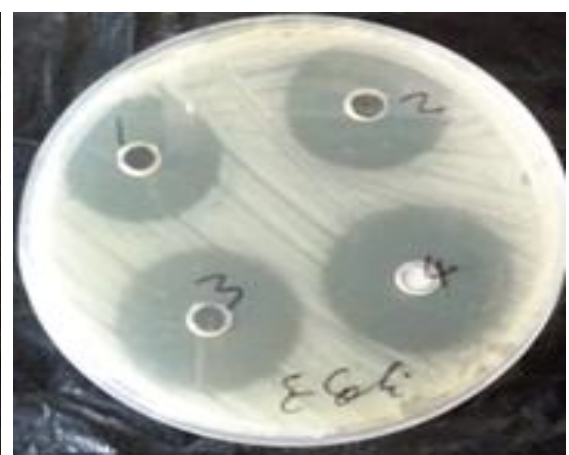

Escherichia coli

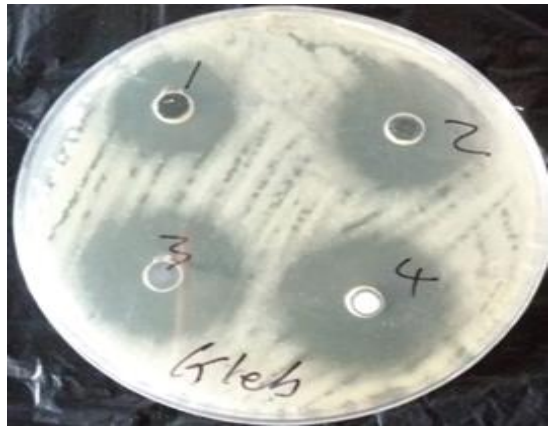

Klebsiella sp.

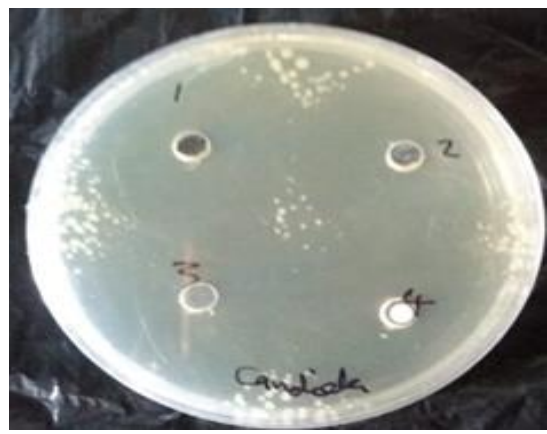

Candida albicans

Figure 3. Antibacterial activities of Spiramycin compound against selected Gram-positive and Gram-negative bacteria and Candida using the well diffusion method.

\subsection{Polarization behavior}

Aluminum corrodes in hydrochloric acid to produce metal ions at the anode and hydrogen gas at the cathode. Spiramycin was added at three concentrations (100, 150 and $200 \mathrm{ppm}$ ) to $0.1 \mathrm{M} \mathrm{HCl}$ medium to reduce the corrosion of $\mathrm{Al}$ at four temperatures $(293,303,313$ and $323 \mathrm{~K}$ ). Figure 4 shows the Tafel plots of inhibition under the experimental conditions indicating the cathodic and anodic regions.

The measured corrosion data are listed in Table 2 showing that the corrosion potentials $\left(E_{\text {corr }}\right)$ shifted to more positive or more negative values compared with the uninhibited solution indicating that this inhibitor is of mixed type. At constant temperature, the corrosion current density $\left(i_{\text {corr }}\right)$ values decreased after adding the inhibitor; i.e., the inhibitor acted as the barrier to isolate the aluminum surface from the medium, indicating that the corrosion rate $(\mathrm{CR})$ also decreased, as calculated using the following equation [32];

$$
C_{\mathrm{R}} m p y=0.13 \cdot i_{\text {corr }} \cdot \frac{e}{\rho}
$$

Tafel slopes ( $b_{\mathrm{c}}$ and $b_{\mathrm{a}}$ ) varied with concentration and temperature due to variation of the reactions at cathodic and anodic sites. 

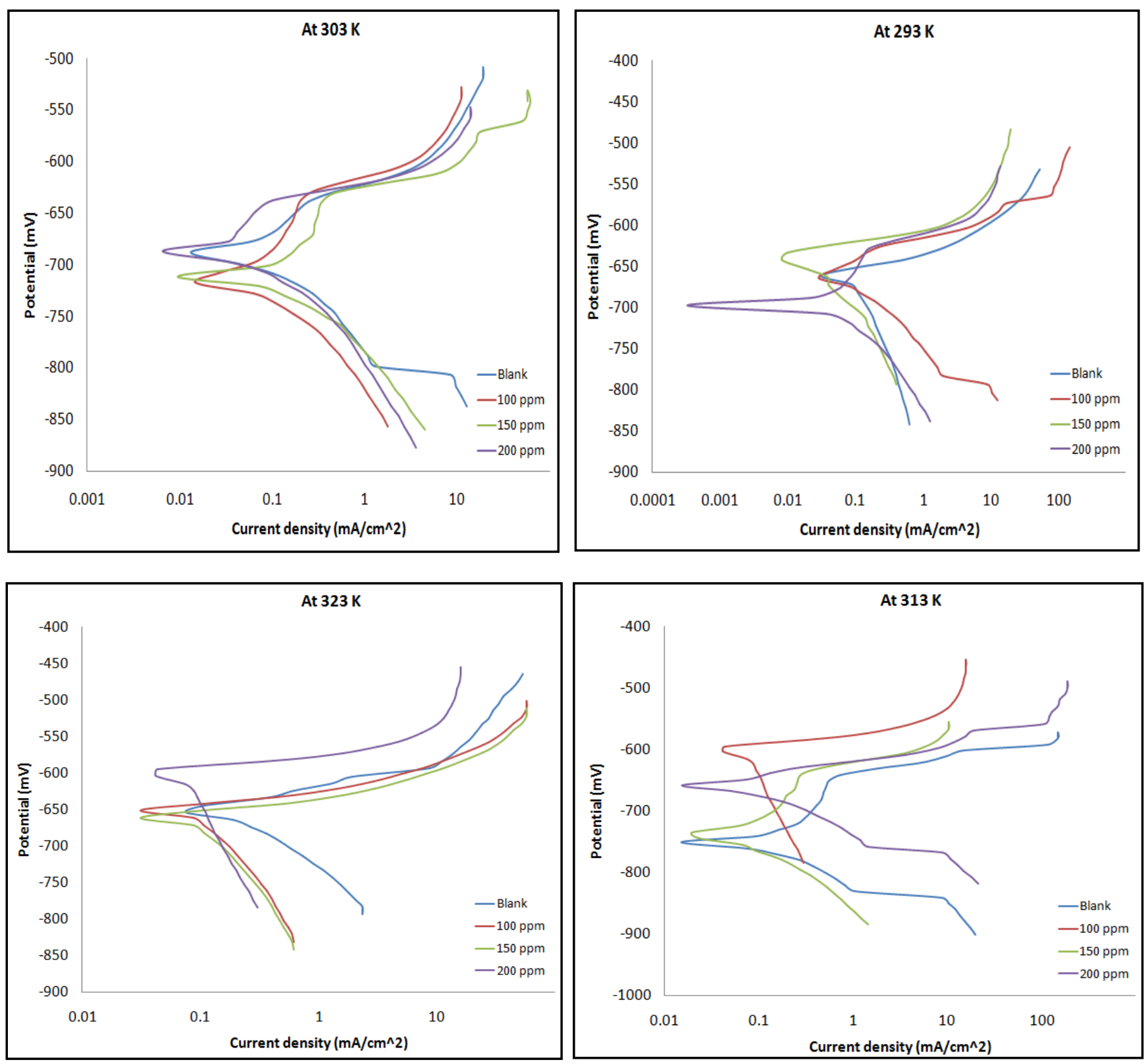

Figure 4. Tafel plots of inhibition by Spiramycin.

Table 2. Measured data of corrosion inhibition by Spiramycin.

\begin{tabular}{|c|c|c|c|c|c|}
\hline \multirow{2}{*}{ Conc., ppm } & \multirow{2}{*}{ Temp., K } & \multirow{2}{*}{$-E_{\text {corr }}, \mathbf{m V}$} & \multirow{2}{*}{$i_{\text {corr }}, \mu \mathrm{A} \cdot \mathbf{c m}^{-2}$} & $-b_{\mathrm{c}}$ & $+b_{\mathrm{a}}$ \\
\hline & & & & \multicolumn{2}{|c|}{$\mathrm{mV} \cdot \operatorname{dec}^{-1}$} \\
\hline \multirow{4}{*}{ Blank } & 293 & 664 & 147 & 195.4 & 69.2 \\
\hline & 303 & 688 & 213 & 90.0 & 254.8 \\
\hline & 313 & 751 & 240 & 119.3 & 88.8 \\
\hline & 323 & 656.5 & 393.4 & 58 & 162.6 \\
\hline
\end{tabular}




\begin{tabular}{|c|c|c|c|c|c|}
\hline \multirow{2}{*}{ Conc., ppm } & \multirow{2}{*}{ Temp., K } & \multirow{2}{*}{$-E_{\text {corr }}, \mathbf{m V}$} & \multirow{2}{*}{$i_{\text {corr }}, \mu \mathrm{A} \cdot \mathbf{c m}^{-2}$} & $-b_{c}$ & $+b_{\mathrm{a}}$ \\
\hline & & & & \multicolumn{2}{|c|}{$\mathrm{mV} \cdot \operatorname{dec}^{-1}$} \\
\hline \multirow{4}{*}{100} & 293 & 665 & 19 & 53.6 & 30.2 \\
\hline & 303 & 718 & 29 & 51.7 & 55.0 \\
\hline & 313 & 595 & 34 & 49.1 & 80.6 \\
\hline & 323 & 694.3 & 68.7 & 301.5 & 16.7 \\
\hline \multirow{4}{*}{150} & 293 & 635 & 11 & 72.0 & 16.5 \\
\hline & 303 & 711 & 16.5 & 27.6 & 40.8 \\
\hline & 313 & 735 & 21 & 34.5 & 37.4 \\
\hline & 323 & 711 & 63.13 & 80.5 & 233.3 \\
\hline \multirow{4}{*}{200} & 293 & 698 & 1.71 & 12.6 & 32.6 \\
\hline & 303 & 687 & 7.37 & 54.9 & 28.3 \\
\hline & 313 & 659 & 9.5 & 23.9 & 36.5 \\
\hline & 323 & 663.1 & 43.34 & 39.6 & 29.6 \\
\hline
\end{tabular}

The corrosion current densities before and after inhibition can be used to calculate inhibition efficiency percentage (IE\%) as follows:

$$
I E \%=\left[1-\frac{i_{\text {corr,inhibited }}}{i_{\text {corr,uninhibited }}}\right] \cdot 100
$$

Where $i_{\text {corr,inhibited }}$ and $i_{\text {corr,uninhibited }}$ denote the corrosion current density in the inhibited and uninhibited media, respectively. The IE\% value listed in Table 3 indicates that $200 \mathrm{ppm}$ of the expired drug is the optimum concentration at $323 \mathrm{~K}$.

Other parameters can also be calculated such as the polarization resistance $\left(R_{\mathrm{p}}\right)$ and porosity percentage $(P P \%)$ for the inhibition process using the following formula [32]:

$$
R_{\mathrm{p}}=\frac{b_{\mathrm{c}} \cdot b_{\mathrm{a}}}{2.303 \cdot i_{\text {corr }}\left(b_{\mathrm{c}}+b_{\mathrm{a}}\right)}
$$

Where $b_{\mathrm{c}}$ and $b_{\mathrm{a}}$ are the cathodic and anodic Tafel slopes, respectively, and $i_{\text {corr }}$ is the corrosion current density.

$$
P P \%=\frac{R_{\mathrm{p}, \text { uninhibited }}}{R_{\mathrm{p}, \text { inhibited }}} 10^{\frac{-\Delta E}{b_{\mathrm{a}}}} \cdot 100
$$

Where $R_{\mathrm{p}, \text { uninhibited }}$ and $R_{\mathrm{p} \text {,inhibited }}$ are the polarization resistances of the uninhibited and inhibited aluminum by the expired drugs, respectively, $\Delta E_{\text {corr }}$ is the corrosion potential difference between the two samples, and $b_{\mathrm{a}}$ is the anodic Tafel slope of the uninhibited 
sample. The optimum concentration at $293 \mathrm{~K}$ exhibited the highest polarization resistance and lowest porosity of the adsorbed films.

It is clear that the inhibitor concentration of $200 \mathrm{ppm}$ gave the highest resistance due to full coverage of the metal surface.

Table 3. Calculated data of corrosion inhibition by Spiramycin.

\begin{tabular}{|c|c|c|c|c|c|}
\hline Conc. ppm & Temp., K & $C_{\mathrm{R}}, \mathbf{m p y}$ & $R_{\mathrm{p}} \cdot 10^{3}, \Omega \cdot \mathrm{cm}^{2}$ & IE\% & PP\% \\
\hline \multirow{4}{*}{ Blank } & 293 & 63.693 & 0.150 & - & - \\
\hline & 303 & 92.290 & 0.135 & - & - \\
\hline & 313 & 103.989 & 0.092 & - & - \\
\hline & 323 & 170.456 & 0.047 & - & - \\
\hline \multirow{4}{*}{100} & 293 & 8.232 & 0.441 & 87.074 & 0.172 \\
\hline & 303 & 12.565 & 0.399 & 86.384 & 1.748 \\
\hline & 313 & 14.731 & 0.389 & 85.833 & 0.944 \\
\hline & 323 & 29.767 & 0.100 & 82.536 & 0.585 \\
\hline \multirow{4}{*}{150} & 293 & 4.766 & 0.529 & 92.517 & 0.716 \\
\hline & 303 & 7.149 & 0.433 & 92.253 & 1.586 \\
\hline & 313 & 9.099 & 0.371 & 91.250 & 0.491 \\
\hline & 323 & 27.353 & 0.411 & 83.952 & 0.462 \\
\hline \multirow{4}{*}{200} & 293 & 0.740 & 2.307 & 98.836 & 0.079 \\
\hline & 303 & 3.193 & 1.100 & 96.539 & 2.051 \\
\hline & 313 & 4.116 & 0.660 & 96.041 & 1.806 \\
\hline & 323 & 18.778 & 0.169 & 88.983 & 0.910 \\
\hline
\end{tabular}

\subsection{Adsorption isotherm}

Studies of the adsorption isotherm lead to know the type of adsorption, i.e., whether it is physical or chemical, which depends on various parameters such as the organic inhibitor and the electrically charged metal surface. The most commonly used isotherm is the Langmuir isotherm given by the following equation:

$$
\frac{C_{\mathrm{inh}}}{\theta}=\frac{1}{K_{\mathrm{ads}}}+C_{\mathrm{inh}}
$$

Where, $K_{\text {ads }}$ is the equilibrium constant of the adsorption-desorption process, $\theta$ is the degree of surface coverage $(\theta=I E / 100)$ and $C_{\text {inh }}$ is the inhibitor concentration in the solution bulk. The plots of $C_{\mathrm{inh}} / \theta(\mathrm{ppm})$ against $C_{\mathrm{inh}}(\mathrm{ppm})$ for the drug at three temperatures are 
straight lines (Figure 5) indicating that Spiramycin obeys the Langmuir isotherm. The linear regression coefficient $\left(R^{2}\right)$ is close to unity.

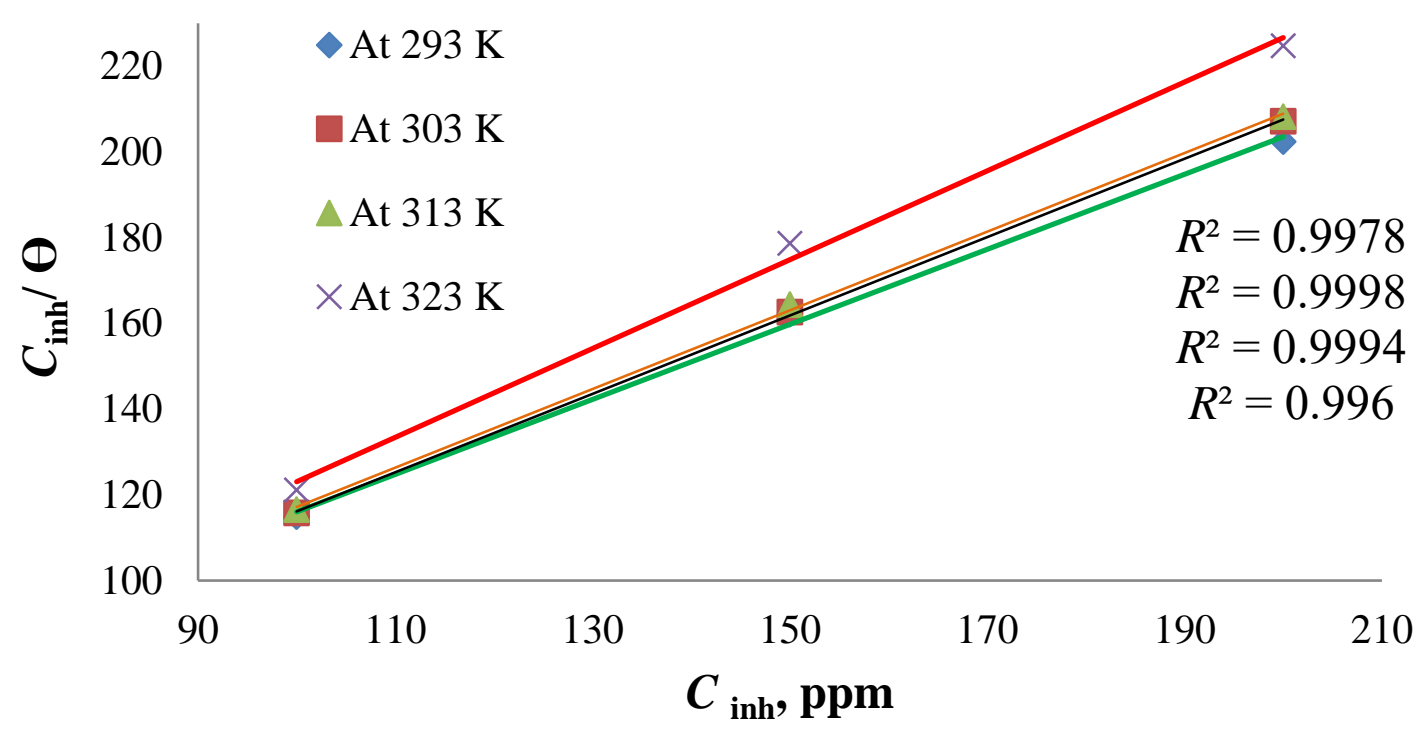

Figure 5. Langmuir isotherm of Spiramycin adsorption on Al.

The apparent free energy of adsorption $\left(\Delta G_{\mathrm{ads}}^{0}\right)$ is calculated from the relation:

$$
\Delta G_{\text {ads }}^{0}=-2.303 R T \cdot \log \left(55.5 K_{\text {ads }}\right)
$$

Where: $K_{\mathrm{ads}}=\theta / C(1-\theta)$.

The negative values of $\Delta G_{\text {ads }}^{0}$ indicate the spontaneous adsorption of the drug and reveal a physical interaction between the inhibitor molecules and the metal surface due to small values of free energy. Also, the values of $K_{\text {ads }}$ are relatively small indicating that the interaction between the adsorbed drug molecules and $\mathrm{Al}$ surface is physical adsorption. The results are shown in Table 4.

The standard adsorption enthalpy change $\Delta H_{\text {ads }}^{0}$ and the standard adsorption entropy change $\Delta S_{\text {ads }}^{0}$ are correlated with standard Gibbs free energy through the relationship:

$$
\Delta G_{\mathrm{ads}}^{0}=\Delta H_{\mathrm{ads}}^{0}-T \Delta S_{\text {ads }}^{0}
$$

$\Delta H_{\mathrm{ads}}^{0}$ and $\Delta S_{\mathrm{ads}}^{0}$ are obtained respectively as the intercept and the negative of the slope of the straight line obtained by plotting $\Delta G_{\text {ads }}^{0}$ versus $T$ (Figure 6). The change in adsorption enthalpy is negative, showing an exothermic process. The exothermic process means either physisorption or chemisorption. The change in standard adsorption entropy is positive, meaning that disorder increases during the adsorption process. This situation can be explained by desorption of water molecules replaced by the inhibitor. 
Table 4. Data of adsorption by Spiramycin.

\begin{tabular}{cccc}
\hline Conc., ppm & Temp., $\mathbf{K}$ & $\boldsymbol{K}_{\text {ads }}$ & $\boldsymbol{\Delta} \boldsymbol{G}_{\text {ads }}^{\mathbf{0}}, \mathbf{k J} \cdot \mathbf{m o l}^{\mathbf{- 1}}$ \\
\hline \multirow{3}{*}{100} & 293 & 0.067 & -3.213 \\
& 303 & 0.063 & -3.171 \\
& 313 & 0.060 & -3.156 \\
& 323 & 0.047 & -2.59 \\
\hline \multirow{3}{*}{150} & 293 & 0.082 & -3.704 \\
& 303 & 0.079 & -3.736 \\
& 313 & 0.069 & -3.514 \\
& 323 & 0.034 & -1.773 \\
\hline \multirow{3}{*}{200} & 293 & 0.424 & -7.699 \\
& 303 & 0.139 & -5.156 \\
& 313 & 0.121 & -4.963 \\
& 323 & 0.040 & -2.167 \\
\hline
\end{tabular}



Figure 6. The relationship between the change in free energy and temperature.

Table 5. Data of Spiramycin adsorption.

\begin{tabular}{ccc}
\hline Conc., $\mathbf{p p m}$ & $\boldsymbol{\Delta} \boldsymbol{H}_{\text {ads }}^{\mathbf{0}}, \mathbf{k J} \cdot \mathbf{m o l}^{\mathbf{1}}$ & $\Delta \boldsymbol{S}_{\text {ads }}^{\mathbf{0}}, \mathbf{k J} \cdot \mathbf{m o l} \mathbf{- 1}^{\mathbf{1}} \cdot \mathbf{K}^{\mathbf{- 1}}$ \\
\hline 100 & -8.835 & 0.0188 \\
150 & -21.70 & 0.0602 \\
200 & -56.70 & 0.1679 \\
\hline
\end{tabular}


To understand the effect of temperature on $\mathrm{CR}$ and $I E \%$ in the corrosion inhibition process, Tafel experiments have been performed in the temperature range between 293 and $323 \mathrm{~K}$ without and with different concentrations of Spiramycin in $\mathrm{HCl}$ solution. Plotting of $1 / T(\mathrm{~K})$ versus $\log \left(C_{\mathrm{R}}\right)$ rate in each experiment was studied with the help of the Arrhenius equation, Figure 7. The apparent activation energy $\left(E_{\mathrm{a}}\right)$ can be calculated through the following equation [33]:

$$
\log C_{\mathrm{R}}=\log A-\frac{E_{\mathrm{a}}}{2.303 R} \cdot \frac{1}{T}
$$

Where $R$ is the gas constant $(8.314 \mathrm{~J} / \mathrm{K} \cdot \mathrm{mol}), A$ is the Arrhenius factor (slope) and $T$ is the temperature of inhibited and uninhibited solution in Kelvin. The data listed in Table 6

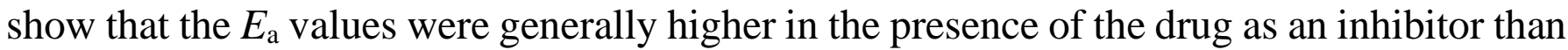
in its absence. This indicates that adsorption decreases with increasing temperature and the adsorption of drug molecules occurs preferentially over $\mathrm{H}_{2} \mathrm{O}$ molecules on the metal surface. Therefore, the optimum concentration (200 ppm) exhibited the highest activation energy.

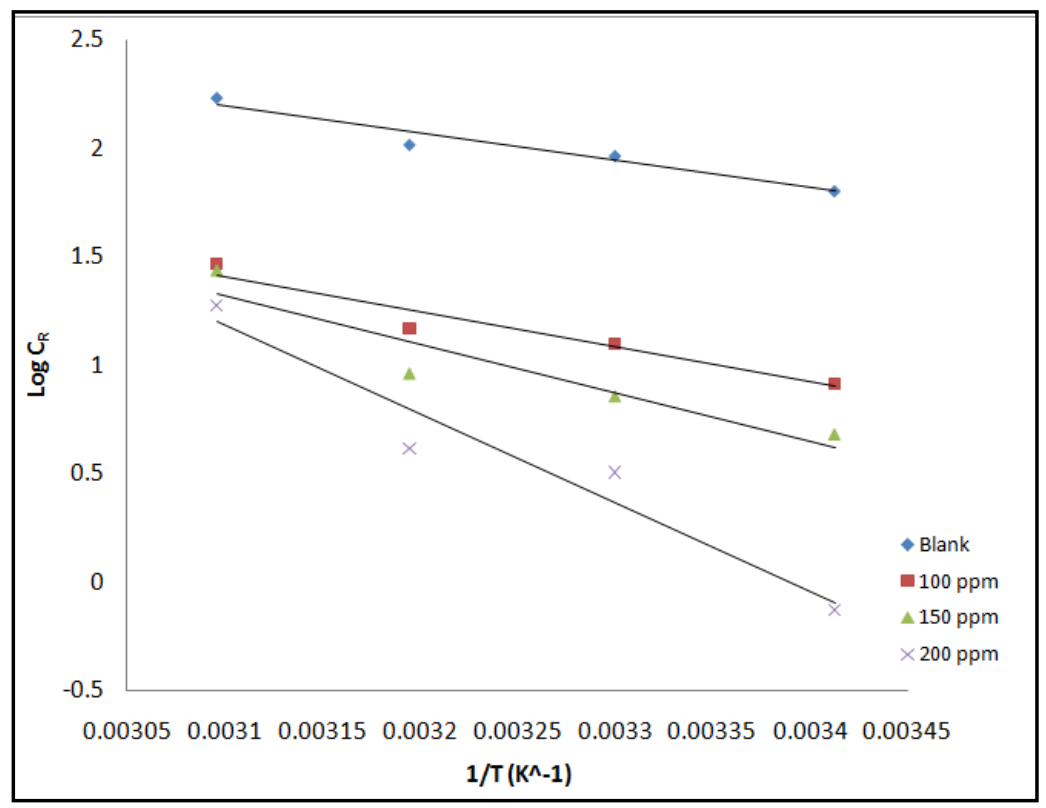

Figure 7. Arrhenius diagram for aluminum in $\mathrm{HCl}$ with and without Spiramycin inhibitor.

Table 6. Activation energies of inhibited and uninhibited solution from 293 to $323 \mathrm{~K}$ of Spiramycin inhibitor in $\mathrm{HCl}$.

\begin{tabular}{cc}
\hline $\boldsymbol{C}$ inh, $\mathbf{p p m}$ & $\boldsymbol{E}_{\mathbf{a}}, \mathbf{k J} \cdot \mathbf{m o l}^{\mathbf{- 1}}$ \\
\hline Blank & 24.10817 \\
100 & 31.43769 \\
150 & 42.77472 \\
200 & 78.2448 \\
\hline
\end{tabular}




\subsection{Examination of the inhibited surface}

The SEM photomicrographs of the surface of polished, corroded and inhibited aluminum samples in the presence of the most efficient concentration $(200 \mathrm{ppm})$ of Spiramycin in $\mathrm{HCl}$ solution are shown in Figure 8. The polished surface of the sample appears to be smooth and displays no corrosion effects, as presented in the SEM image of the sample in Figure 8a,b, while the aluminum surface in the absence of Spiramycin inhibitor shown in Figure 8c,d displayed a few pits and cracks compared to the polished surface as a result to its exposure to corrosive solution. On the other hand, the surface of aluminum was covered by a film of the inhibitor molecules as seen in Figure 8e,f which is confirmed by increasing the thickness and roughness of the surface in AFM photomicrograph, also, the number of cracks and pits decreased clearly in the SEM image for the inhibited surface.

EDXs analysis was utilized to estimate the composition of the elements on uninhibited, corroded and inhibited surface of aluminum samples in $\mathrm{HCl}$ solution.

The EDXs spectra of the tested specimens are shown in Figure 9a-c. The percentage atomic content of aluminum on the polished, corroded and inhibited samples is $95.2 \%$, $78.5 \%$ and $90.2 \%$, respectively. It appeared from the EDXs analyses that the spectra of the corroded and inhibited coupons (Figure 9b,c) show a decrease in Al content compared to the spectrum of the polished sample (Figure 9a), which is due to the dissolution of aluminum atoms as a result of corrosion in the corrosive environment. In addition to that, the resulting spectrum of inhibited sample (Figure 9c) includes a peak corresponding to an element within Spiramycin $(\mathrm{O})$ which indicates the adsorption of the inhibitor molecules on the surface of aluminum.

Furthermore, a decrease in $\mathrm{Al}$ content on the inhibited sample resulted from the formation of a protective layer on the aluminum surface. On the other hand, the EDXs spectra of the corroded sample showed a peak that corresponds to the $\mathrm{Cl}$ element resulting from the presence of the corrosive solution.

The FT-IR spectroscopy technique was utilized to identify the differences between the stretching vibrations of the functional groups in Spiramycin inhibitor and a film formed after adsorption of drug molecules on aluminum surface. Figure 10 illustrates the FT-IR spectra of Spiramycin inhibitor and the adsorbed film on the metal surface: the peak at $3485 \mathrm{~cm}^{-1}$ is attributed to $\mathrm{O}-\mathrm{H}$ stretching vibration, and stretching of $\mathrm{C}-\mathrm{H}$ aliphatic is at $2933 \mathrm{~cm}^{-1}$. In addition to that, $\mathrm{C}=\mathrm{O}$ stretching appears at $1722 \mathrm{~cm}^{-1}$ and $\mathrm{C}=\mathrm{C}$ stretching aromatic is around $1675 \mathrm{~cm}^{-1}$. C-N and $\mathrm{C}-\mathrm{O}$ appear in the range from 1000 to $1350 \mathrm{~cm}^{-1}$. The FT-IR spectrum of the inhibited layer obviously showed a decrease in the intensity of all stretching bands recorded in Spiramycin. According to the results obtained, it can be seen that the functional groups and active centers in Spiramycin inhibitor interacted with the Al surface and formed a protective film against corrosion, especially for the $\mathrm{O}-\mathrm{H}$ group. This indicates that this group is attracted to the metal by adsorption to form an $\mathrm{Al}-$ drug complex. 

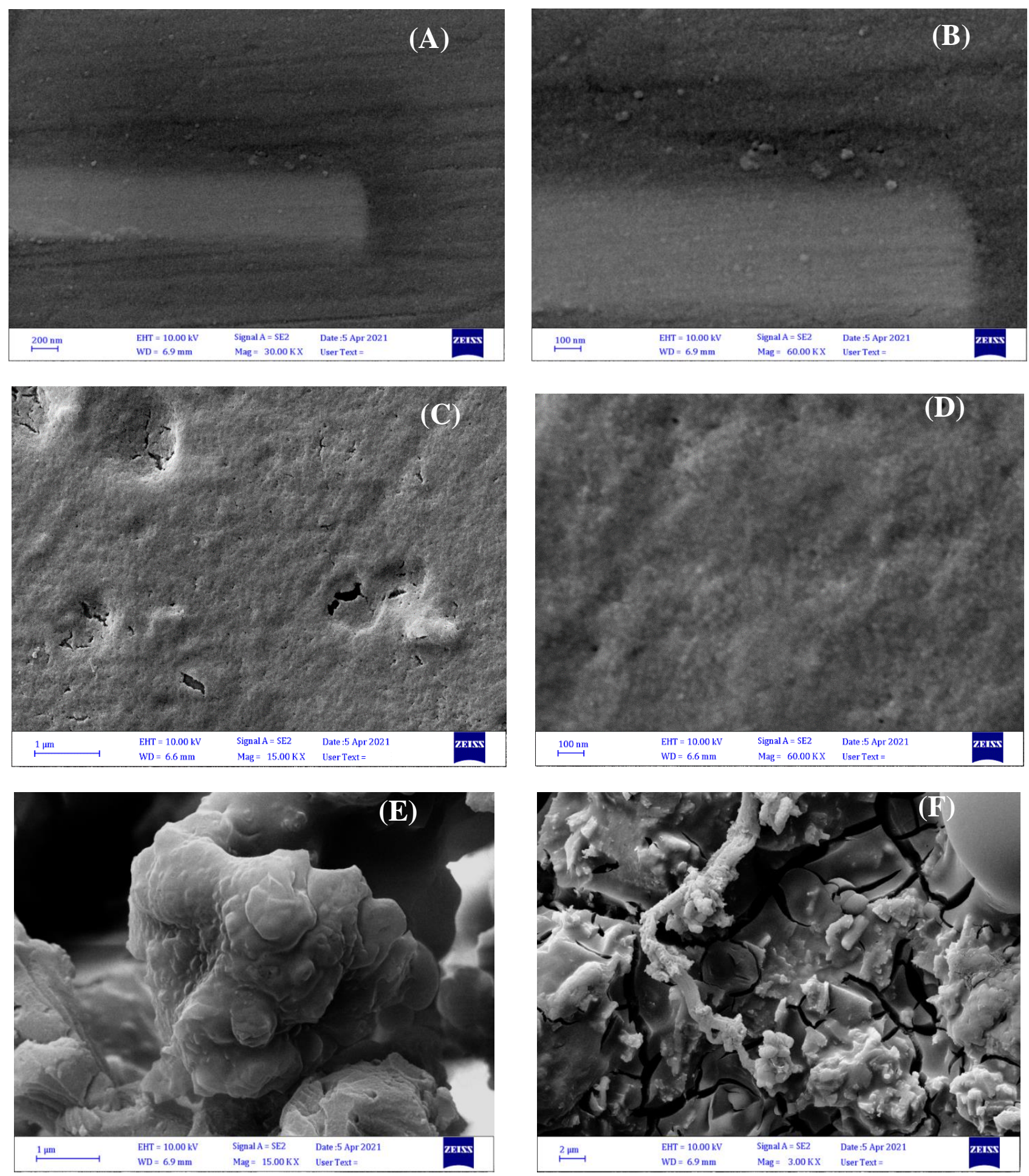

Figure 8. SEM micrographs of aluminum surface $(\mathrm{a}, \mathrm{b})$ before immersion in $0.1 \mathrm{M} \mathrm{HCl},(\mathrm{c}, \mathrm{d})$ after corrosion in $0.1 \mathrm{M} \mathrm{HCl},(\mathrm{e}, \mathrm{f})$ after inhibition in $0.1 \mathrm{M} \mathrm{HCl}+200 \mathrm{ppm}$ of the drug. 



Figure 9. EDXs analyses of aluminum: a) polished specimen, b) corroded in $\mathrm{HCl}$ medium, c) samples inhibited by 200 ppm Spiramycin inhibitor. 


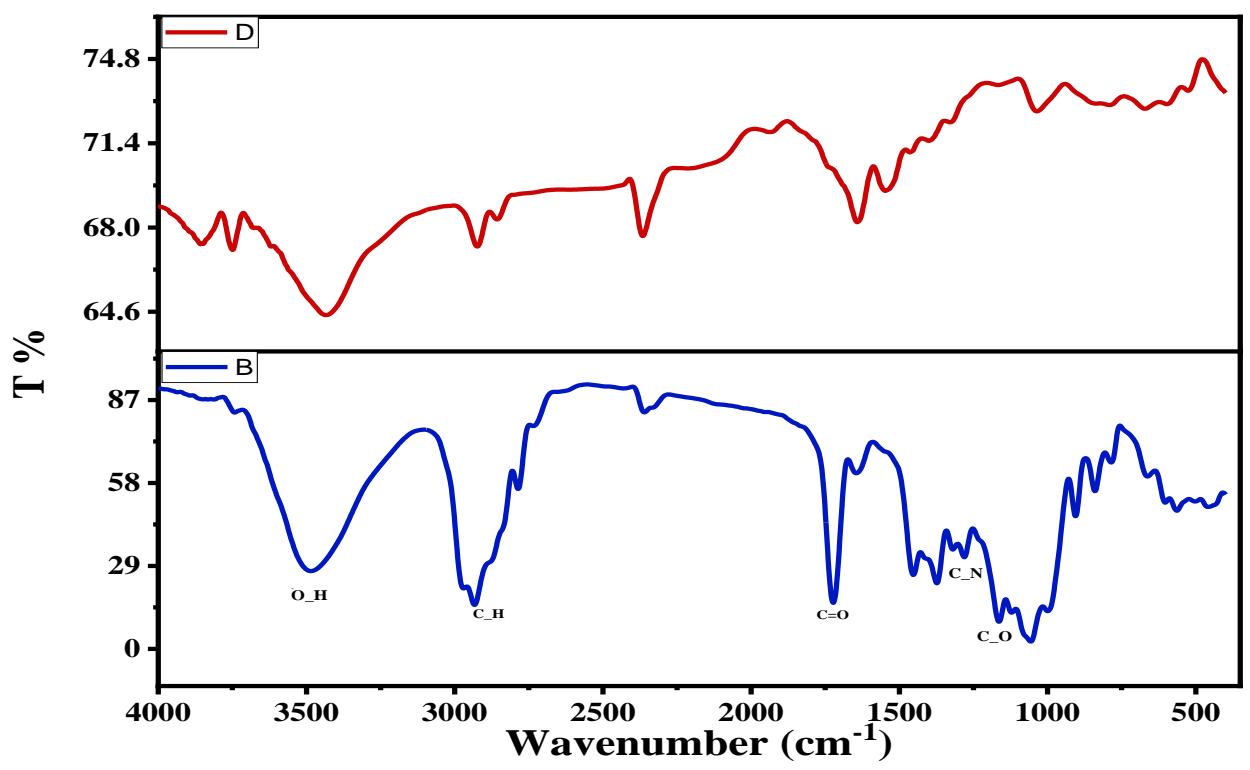

Figure 10. FTIR spectra of Spiramycin (blue line) and film formed after adsorption on aluminum surface (red line, $200 \mathrm{ppm}$ ).

Atomic Force Microscopy (AFM) Characterization the Figure 11 shows the 2D and 3D images of the polished, corroded, and inhibited samples in the presence of $200 \mathrm{ppm}$ of expired Spiramycin in the medium. These images show that the maximum peak-to-valley (in 3D images) was observed for the corroded sample $(11.9 \mathrm{~nm})$, while the minimum value occurred in the sample inhibited by $200 \mathrm{ppm}$ of the drug $(11.0 \mathrm{~nm})$ due to the formation of a compact adsorbed inhibitor layer. The $4.6 \mathrm{~nm}$ peak-to-valley depth for the polished sample can be attributed to atmospheric corrosion. These data indicate that the aluminum surface immersed in the acid medium has a greater surface roughness than that of the polished metal, indicating that the unprotected aluminum surface is rougher and this is due to the corrosion of aluminum in $\mathrm{HCl}$ bulk. The average roughness values were calculated using AFM analysis, and the results are listed in Table 9.

Table 9. Data of AFM analysis.

\begin{tabular}{ccccc}
\hline Sample & $\begin{array}{c}\text { Root-mean square } \\
\text { height, nm }\end{array}$ & $\begin{array}{c}\text { Maximum } \\
\text { height, } \mathbf{~ n m}\end{array}$ & $\begin{array}{c}\text { Arithmetic mean } \\
\text { height, nm }\end{array}$ & $\begin{array}{c}\text { Developed } \\
\text { interfacial area } \\
\text { ratio, \% }\end{array}$ \\
\hline Polished sample & 4.541 & 26.06 & 3.447 & 54.98 \\
Corroded sample & 5.871 & 33.09 & 4.717 & 161.5 \\
$\begin{array}{c}\text { Inhibited sample at } \\
\text { 200 ppm }\end{array}$ & 9.860 & 55.04 & 7.828 & 142.5 \\
\hline
\end{tabular}

The results show that the average roughness of the polished aluminum surface is about $4.54 \mathrm{~nm}$, while the roughness increased to $5.87 \mathrm{~nm}$ in the corroded sample as shown in 
Figure $11 \mathrm{c}, \mathrm{d}$. On the other hand, the average roughness of the sample inhibited by $200 \mathrm{ppm}$ of Spiramycin inhibitor molecules increased to $9.86 \mathrm{~nm}$, and the increase in average roughness of the inhibited sample resulted from the of inhibitor molecules as cluster groups on aluminum surface [34].

Figure 12 shows the granularity cumulating distribution charts for the different samples, which show different distributions of particles with different average diameters on the aluminum surface.
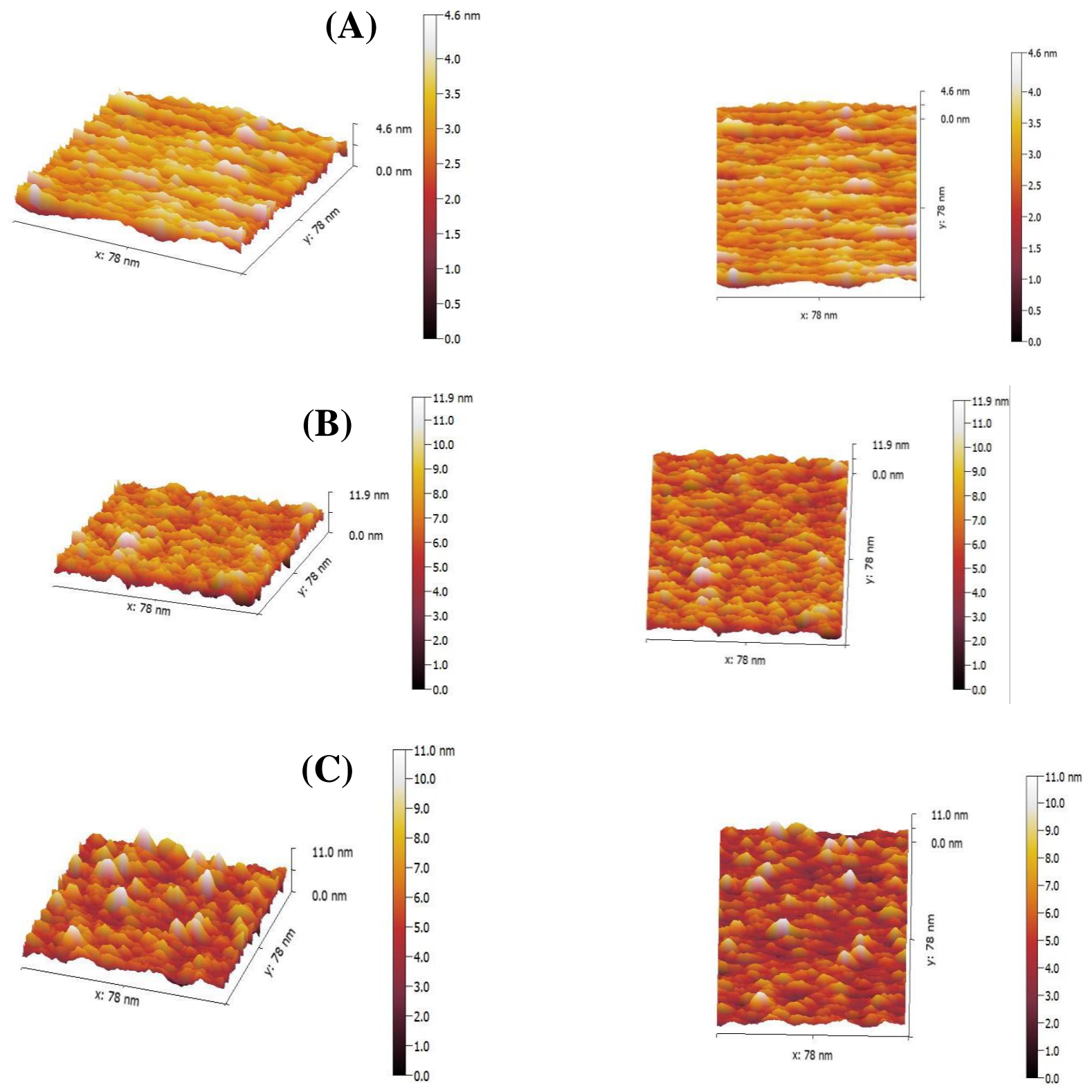

Figure 11. 2D and 3D images of (a) polished, (b) corroded, (c) inhibited sample with $200 \mathrm{ppm}$ of the drug. 

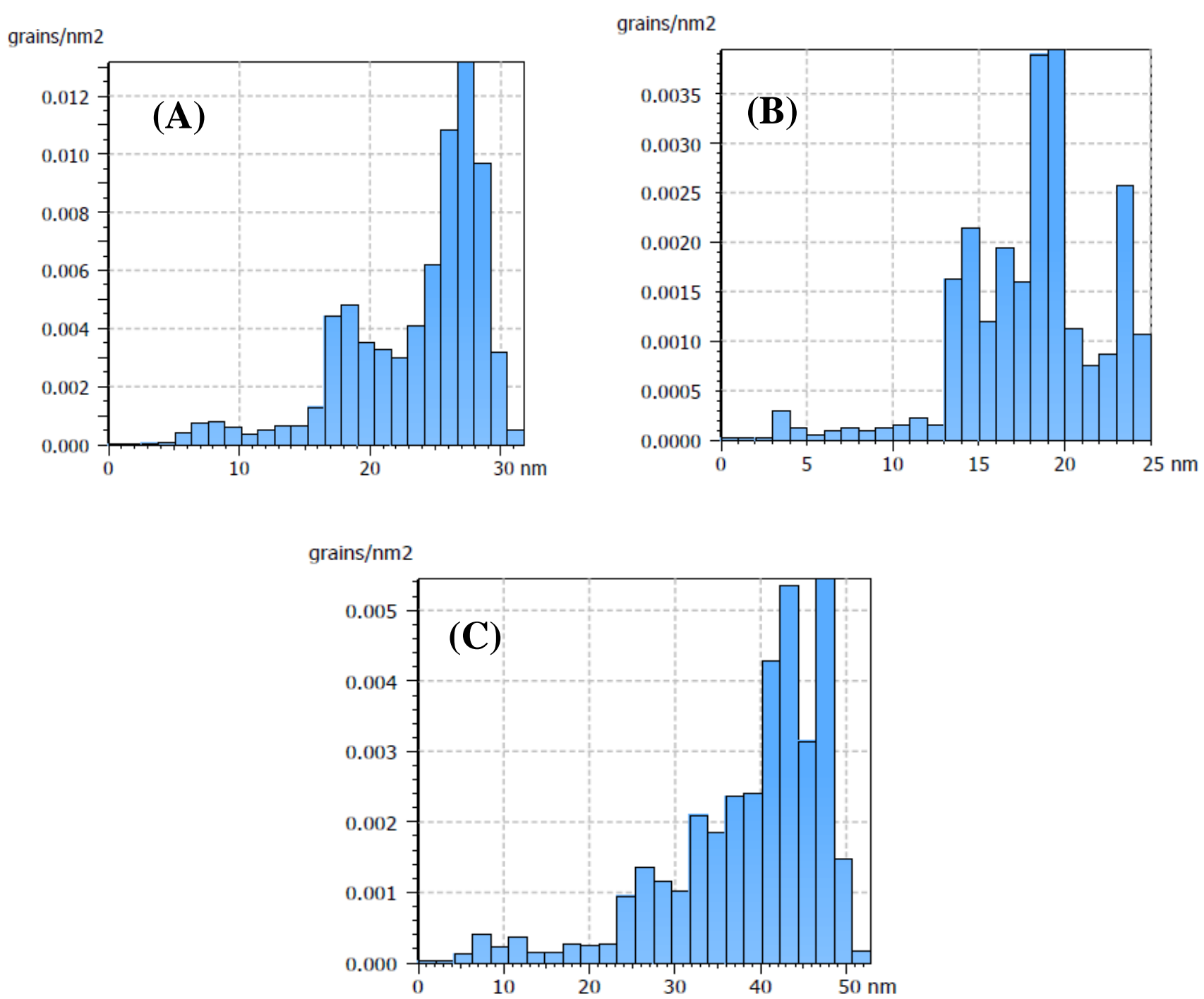

Figure 12. Granularity accumulation distribution of particles for (a) polished, (b) corroded, (c) inhibited sample with $200 \mathrm{ppm}$ of the drug.

\section{Mechanism of inhibition}

It is known that the efficiency of the inhibitor is affected by many factors including the chemical composition of the inhibitor through the abundance of electrons and the method of their distribution on the molecule in addition to the nature of the corrosive environment and the metal surface [35]. According to the data obtained from the adsorption study and based on the Gibbs free energy and enthalpy values, the type of adsorption that occurs between the Spiramycin molecules and the surface of the metal is of physical type.

The expired drug acts as a corrosion inhibitor for aluminum in $0.1 \mathrm{M} \mathrm{HCl}$ by adsorbing on anodic sites due to the hetero atoms in the drug structure ( $\mathrm{N}$ and $\mathrm{O}$ atoms). In addition, the molecule contains high electron densities that strongly interact with the positive charge of $\mathrm{Al}$ ions at a pure aluminum/solution interface to form $\mathrm{Al}$ ion/drug complexes. These complexes act as a barrier to shield the metallic surface from the corrosive medium. 


\section{Conclusion}

1. The evaluation of Tafel measurements for the inhibited solutions revealed that Spiramycin suppresses the dissolution of $\mathrm{Al}$ and acts as an anti-corrosive agent with an inhibition efficiency reaching $98.84 \%$ at $293 \mathrm{~K}$ and $200 \mathrm{ppm}$.

2. According to the polarization behavior of Spiramycin inhibitor, it can be classified as a mixed-type inhibitor.

3. Increasing the temperature of the inhibited solutions from 293 to $323 \mathrm{~K}$ led to a decrease in the inhibition efficiency of the inhibitor at each concentration.

4. The adsorption of Spiramycin inhibitor on aluminum surface obeys the Langmuir model at all the tested temperatures and the adsorption type was classified as physisorption.

5. The negative values of the $\Delta G_{\text {ads }}^{\mathrm{o}}$ parameter for the inhibitor solutions indicate that the adsorption process between the inhibitor molecules and the metal surface is spontaneous.

6. The results of SEM-EDXs, AFM and FT-IR examination showed good evidence that a Spiramycin aluminum layer was formed.

7. The biological activity of Spiramycin against corrosive bacteria indicates that it has a good antibacterial activity against both gram-positive and negative bacterial cultures in addition to its corrosion efficiency.

\section{Acknowledgements}

We appreciate the staff of the Department of Applied Sciences, University of Technology, for cooperation and fulfilling the requirements of this study. In addition, we thank Al-Mustansiriya University, College Science's for their help in antibacterial testing and thank the Ministry of Science and Technology for their help in acquiring FT-IR spectra and performing HPLC assay.

\section{Conflict of Interest}

The authors declare no conflict of interest.

\section{References}

1. O. Meena and A. Chaturvedi, Corrosion Inhibition of Aluminium by Extract of Aerial Parts of Phyllanthus niruri in Hydrochloric acid and Study of Extract as Antibacterial, $J$. Appl. Chem., 2020, 13, 22-32. doi: 10.9790/5736-1307012232

2. K.N. Rathod and R.T. Vashi, Inhibition effect of ammonium dichromate on the corrosion of aluminium in phosphoric acid, Int. J. Chem. Stud., 2016, 4, 37-42.

3. O.S.I. Fayomi and I.G. Akande, Corrosion Mitigation of Aluminium in $3.65 \% \mathrm{NaCl}$ Medium Using Hexamine, J. Bio- Tribo-Corrosion, 2019, 5. doi: 10.1007/s40735-018$\underline{0214-4}$ 
4. E.A. Yaqo, R.A. Anaee, M.H. Abdulmajeed, I.H.R. Tomi, and M.M. Kadhim, Electrochemical, morphological and theoretical studies of an oxadiazole derivative as an anti-corrosive agent for kerosene reservoirs in Iraqi refineries, Chem. Pap., 2020, 74, 1739-1757. doi: 10.1007/s11696-019-01022-2

5. M.H. Abdulmajeed, H.A. Abdullah, and S.I. Ibrahim, Investigation of Corrosion Protection for Steel by Eco-Friendly Coating Investigation of Corrosion Protection for Steel by Eco-Friendly Coating, Engineering and Technology Journal, 2019, 37, 52-59. doi: $10.30684 /$ etj.37.2A.3

6. R.K. Pathak and P. Mishra, Drugs as Corrosion: A Review, Int. J. Sci. Res., 2016, 5, 671-677. doi: 10.21275/v5i4.nov162623

7. N.K. Gupta, C.S.A. Gopal, V. Srivastava, and M.A. Quraishi, Application of expired drugs in corrosion inhibition of mild steel, Int. J. Pharm. Chem. Anal., 2017, 4, 8-12.

8. R.A. Anaee, I.H.R. Tomi, M.H. Abdulmajeed, S.A. Naser, and M.M. Kathem, Expired Etoricoxib as a corrosion inhibitor for steel in acidic solution, J. Mol. Liq., 2019, 279, 594-602. doi: 10.1016/j.molliq.2019.01.169

9. J.I. Bhat and V.D.P. Alva, A study of aluminium corrosion inhibition in acid medium by an antiemitic drug, Trans. Indian Inst. Met., 2011, 64, 377-384. doi: 10.1007/s12666$\underline{011-0102-9}$

10. M. Abdallah, I. Zaafarany, S.O. Al-Karanee, and A.A.A. El-Fattah, Antihypertensive drugs as an inhibitors for corrosion of aluminum and aluminum silicon alloys in aqueous solutions, Arab. J. Chem., 2012, 5, 225-234. doi: 10.1016/j.arabjc.2010.08.017

11. M.M. Fares, A.K. Maayta, and J.A. Al-Mustafa, Synergistic corrosion inhibition of aluminum by polyethylene glycol and ciprofloxacin in acidic media, J. Adhes. Sci. Technol., 2013, 27, 2495-2506. doi: 10.1080/01694243.2013.787584

12. M. Abdallah and B.A. Al Jahdaly, Gentamicin, kanamycin and amikacin drugs as nontoxic inhibitors for corrosion of aluminum in $1.0 \mathrm{M}$ hydrochloric acid, Int. J. Electrochem. Sci., 2015, 10, 9808-9823.

13. R.S.A. Hameed, E.A. Ismail, A.H. Abu-Nawwas, and H.I. Al-Shafey, Expired voltaren drugs as corrosion inhibitor for aluminium in hydrochloric acid, Int. J. Electrochem. Sci., 2015, 10, 2098-2109.

14. P.O. Ameh and U.M. Sani, Cefuroxime axetil: A commercially available drug as corrosion inhibitor for aluminum in hydrochloric acid solution, Port. Electrochim. Acta, 2016, 34, 131-141. doi: 10.4152/pea.201602131

15. C.U. Ibeji, D.C. Akintayo, and I.A. Adejoro, The Efficiency of Chloroquine as Corrosion Inhibitor for Aluminium in $1 \mathrm{M} \mathrm{HCl}$ Solution : Experimental and DFT Study, Jordan J. Chem., 2016, 11, 38-49. doi: 10.12816/0026487

16. I.S. Sivokon and E.I. Sivokon, Application of coupons made of metal galvanic couples for corrosion monitoring and estimation of the efficiency of inhibitors, Int. J. Corros. Scale Inhib., 2021, 10, no. 3, 900-910. doi: 10.17675/2305-6894-2021-10-3-4 
17. R.H.B. Beda, P.M. Niamien, E.B. Avo Bilé, and A. Trokourey, Inhibition of Aluminium Corrosion in 1.0 M HCl by Caffeine: Experimental and DFT Studies, Adv. Chem., 2017, 2017, 1-10. doi: $10.1155 / 2017 / 6975248$

18. S.M. Habibi-Khorassani, M. Shahraki, M. Noroozifar, M. Darijani，M. Dehdab, and Z. Yavari, Inhibition of aluminum corrosion in acid solution by environmentally friendly antibacterial corrosion inhibitors: Experimental and theoretical investigations, Prot. Met. Phys. Chem. Surfaces, 2017, 53, 579-590. doi: 10.1134/S2070205117030078

19. N. Ismail, H. Megahed, A. Ali, and M.A. Etre, Application of theophylline anhydrous as inhibitor for acid corrosion of aluminum, Egypt. J. Chem., 2017, 60, 95-107. doi: 10.21608/ejchem.2017.631.1011

20. Z. Yavari, M. Darijani, and M. Dehdab, Comparative Theoretical and Experimental Studies on Corrosion Inhibition of Aluminum in Acidic Media by the Antibiotics Drugs, Iran. J. Sci. Technol. Trans. A Sci., 2018, 42, 1957-1967. doi: 10.1007/s40995-017$\underline{0358-\mathrm{y}}$

21. N.Y.S. Diki, G.K. Gbassi, A. Ouedraogo, M. Berte, and A. Trokourey, Aluminum corrosion inhibition by cefixime drug: experimental and DFT studies, J. Electrochem. Sci. Eng., 2018, 8, 303-320. doi: 10.5599/jese.585

22. N. Raghavendra, Application of Expired Alprazolam Drug as Corrosion Inhibitor for Aluminum in $3 \mathrm{M} \mathrm{HCl}$ Environment, J. Sci., Eng. Technol., 2018, 6, 35-42.

23. N. Diki, Y. Silvère, B.K. Valery, M. Guy-Richard and O. Augustin, Cefadroxil Drug as Corrosion Inhibitor for Aluminum in $1 \mathrm{M} \mathrm{HCl} \mathrm{Medium:} \mathrm{Experimental} \mathrm{and} \mathrm{Theoretical}$ Studies, 2018, 11, 24-36. doi: 10.9790/5736-1104012436

24. M. Abdallah, E.A.M. Gad, M. Sobhi, J.H. Al-Fahemi, and M.M. Alfakeer, Performance of tramadol drug as a safe inhibitor for aluminum corrosion in $1.0 \mathrm{M} \mathrm{HCl}$ solution and understanding mechanism of inhibition using DFT, Egypt. J. Pet., 2019, 28, 173-181. doi: $10.1016 /$ j.ejpe.2019.02.003

25. O.S.I. Fayomi, I.G. Akande, A.P.I. Popoola, and H. Molifi, Potentiodynamic polarization studies of Cefadroxil and Dicloxacillin drugs on the corrosion susceptibility of aluminium AA6063 in 0.5 M nitric acid, J. Mater. Res. Technol., 2019, 8, 3088-3096. doi: $10.1016 /$ j.jmrt.2018.12.028

26. S. Bashir, V. Sharma, S. Kumar, Z. Ghelichkhah, I.B. Obot, and A. Kumar, Inhibition performances of nicotinamide against aluminum corrosion in an acidic medium, Port. Electrochim. Acta, 2020, 38, 107-123. doi: 10.4152/pea.202002107

27. N. Raghavendra, Antifebrin Drug Prepared via One-Stage Green Method as Sustainable Corrosion Inhibitor for $\mathrm{Al}$ in $3 \mathrm{M} \mathrm{HCl}$ Medium: Insight from Electrochemical, Gasometric, and Quantum Chemical Studies, Surf. Eng. Appl. Electrochem., 2020, 56, 235-241. doi: 10.3103/S106837552002012X

28. S. Bashir, H. Lgaz, I.M. Chung and A. Kumar, Effective green corrosion inhibition of aluminium using analgin in acidic medium: an experimental and theoretical study, Chem. Eng. Commun., 2020, 208, 1121-11130. doi: $\underline{10.1080 / 00986445.2020 .1752680}$ 
29. N. Raghavendra, Expired naproxen drug as a robust corrosion inhibitor of $\mathrm{Al}$ in $3 \mathrm{M}$ hydrochloric acid system, Songklanakarin J. Sci. Technol., 2020, 42, 917-922.

30. M. Abdallah, M.I. Awad, H.M. Altass, M. Morad, M.A. Eletre, J.H. Al-Fahemi and W.M. Sayed, Sildenafil drug as a safe anticorrosion for 6063 aluminum alloy in acidic and alkaline solutions: Theoretical and experimental studies, Egypt. J. Pet., 2020, 29, 211-218. doi: 10.1016/j.ejpe.2020.06.001

31. I.G. Akande, O.S.I. Fayomi and O.O. Oluwole, Anticorrosion Potential of Inhibitive Suphtrim Drug on Aluminium Alloys in $0.5 \mathrm{M} \mathrm{H}_{2} \mathrm{SO}_{4}$, J. Bio- Tribo-Corrosion, 2020, 6, 1-8. doi: $10.1007 / \mathrm{s} 40735-020-00429-9$

32. R.A. Anaee, Behavior of Ti/HA in Saliva at Different Temperatures as Restorative Materials, J. Bio- Tribo-Corrosion, 2016, 2, 1-9. doi: 10.1007/s40735-016-0036-1

33. A. Chaouiki, H. Lgazc, I.M. Chung, I.H. Ali, L. Gaonkar, K.S. Bhat, R. Salghi, H. Oudda and M.I. Khan, Understanding corrosion inhibition of mild steel in acid medium by new benzonitriles: Insights from experimental and computational studies, $J$. Mol. Liq., 2018, 266, 603-616. doi: 10.1016/j.molliq.2018.06.103

34. M.R. Arshadi, M. Lashgari, and G.A. Parsafar, Cluster approach to corrosion inhibition problems: Interaction studies, Mater. Chem. Phys., 2004, 86, 311-314. doi: 10.1016/j.matchemphys.2004.03.028

35. C.D. Taylor, A. Chandra, J. Vera and N. Sridhar, Multiphysics modelling, quantum chemistry and risk analysis for corrosion inhibitor design and lifetime prediction, Faraday Discuss., 2015 180, 459-477. doi: 10.1039/c4fd00220b 